\title{
La canne à sucre dans le bagne calédonien (1873-1894)
}

\section{Alain Saussol}

\section{OpenEdition}

12 Journals

Édition électronique

URL : http://journals.openedition.org/jso/1492

DOI : $10.4000 /$ jso. 1492

ISSN : 1760-7256

\section{Éditeur}

Société des océanistes

\section{Édition imprimée}

Date de publication : 1 décembre 2002

Pagination : 173-180

ISSN : 0300-953x

\section{Référence électronique}

Alain Saussol, « La canne à sucre dans le bagne calédonien (1873-1894) », Journal de la Société des Océanistes [En ligne], 114-115 | Année 2002, mis en ligne le 26 mai 2008, consulté le 22 mars 2021. URL : http://journals.openedition.org/jso/1492 ; DOI : https://doi.org/10.4000/jso.1492

\section{(c) $(1) \odot$}




\section{La canne à sucre dans le bagne calédonien (1873-1894)*}

par

Alain SAUSSOL **

\section{RÉSUMÉ}

Entre 1873 et 1894, l'administration pénitentiaire en Nouvelle-Calédonie a tenté de développer la culture et la transformation de la canne à sucre à Bourail et dans la vallée de la Dumbéa. Cette note relate l'histoire de cette tentative et de son échec.

Mots-CLÉS : Nouvelle-Calédonie, canne à sucre, sucre, rhum, bagne, colonisation pénale.

Jacques Barrau reste mon premier souvenir calédonien. C'était au début de décembre 1964, au débarqué du cargo qui m'avait amené pour la première fois à Nouméa. Je n'y connaissais personne mais j'avais, comme viatique, un nom, Jacques Barrau à la Commission du Pacifique Sud, un spécialiste de l'horticulture mélanésienne qu'on m'avait conseillé d'aller voir à mon arrivée. Passé la douane, j'allais donc à l'anse Vata. Un bureau clair et spartiate, au bout d'un de ces longs bâtiments préfabriqués construits par l'armée américaine, aujourd'hui rasés. Le maître des lieux était chef de la Section du Développement économique, un personnage immense, aux cheveux ras, aux lunettes d'écaille, à la fois massif et chaleureux. M'étant présenté, je lui demandai conseil pour savoir où poser mes cantines. Il m'écouta, réfléchit, puis dit qu'il

\section{ABSTRACT}

From 1873 to 1894, penal administration in New Caledonia attempted to develop cultivation and processing of sugar cane at Bourail and in the Dumbea valley. This paper relates the story of this attempt and its unsuccess.

KeYwords : New Caledonia, sugar cane, sugar, rum, convict prison, penal colonization.

allait voir s'il pouvait m'obtenir une chambre de passage de la Commission, ajoutant que cela ne s'était jamais fait, qu'il ne promettait rien mais qu'il allait essayer. Dix minutes plus tard il revenait avec un grand sourire. "Cest gagné dit-il, suivez moi, je vais vous montrer où vous installer ». L'installation dura trois ans.

Tel fut mon premier contact avec Jacques Barrau qui s'envolait quelques jours plus tard pour une chaire de professeur à l'Université de Yale. Je le revis ensuite. J'eus même le privilège de l'accompagner à différentes reprises dans ses tournées en brousse, à Bourail et sur la propriété familiale du Gabé, mais aussi à Pouembout et Koné. Temps forts et moments privilégiés pour profiter de son expérience, de son immense culture et de ses compétences multiples tant en botanique qu'en matière d'agriculture ou de

* Cette note prolonge un article publié dans le Journal des Océanistes, 82-83 (1986), sous le titre « Des créoles sucriers en Nouvelle-Calédonie, ou l'échec d'une économie de plantation ».

** Professeur de géographie à l'Université de Montpellier. 
développement rural, mais aussi de sa profonde connaissance de la société calédonienne dont il était un indéniable expert. Plus tard encore, il me fera l'honneur et l'amitié de participer à mon jury de thèse. C'est dire combien, pour ma part, ce bien modeste hommage est d'abord l'occasion d'acquitter une dette.

L'engouement pour la canne en NouvelleCalédonie, stimulé vers 1870 par les colons bourbonnais, devait susciter l'intérêt pour cette culture d'une Administration pénitentiaire soucieuse d'occuper ses concessionnaires dont le nombre allait croissant. Celle-ci avait le choix entre le café et la canne. Elle choisit la seconde, qui lui semblait avoir quelques chances de succès mais, surtout, séduite par une offre de l'industriel Higginson qui, spéculant alors sur le sucre, lui avait proposé une association.

C'est avec Higginson que l'Administration pénitentiaire va traiter à deux reprises, à sept ans d'intervalle, pour développer la culture de la canne à sucre en deux endroits de la brousse calédonienne : à Bourail dès 1873 et, à partir de 1880, à Koé, dans la vallée de la Dumbéa.

\section{Bourail : les vicissitudes de l'usine de Bacouya}

Dès la fondation de Bourail, la direction du Pénitencier avait envisagé de faire cultiver la canne par ses concessionnaires, celle-ci ayant la réputation de bien résister aux inondations (Doucin, 1875). Or Higginson, qui avait reconnu le réseau des belles vallées confluentes de Bourail, n'était pas insensible à la promesse du gouverneur Guillain, faite en 1865, d'accorder une concession gratuite de 500 hectares aux deux premiers industriels qui installeraient des sucreries en Nouvelle-Calédonie. Rappellons qu'à cette époque, la Calédonie minière n'a pas encore surgi. Le cuivre de Ouégoa ne sera découvert qu'en 1872 et le nickel en 1873 au Mont d'Or (bien que sa présence ait été déjà pressentie par J. Garnier). Aussi, le sucre apparaît-il comme une spéculation industrielle possible pour les affairistes de l'oligarchie nouméenne naissante. S'y impliquent ceux-là mêmes qui investiront plus tard dans les mines.

D'autant que le gouvernement l'encourage et offre des primes. Séduit par celles-ci, Higginson intéresse à l'affaire un banquier néo-zélandais, Cruickshand. Ce dernier entre en contact avec le colonel Charrière, tout-puissant directeur de l'Administration pénitentiaire, et lui fait miroiter des possibilités d'exportation de sucre vers l'Australie et la Nouvelle-Zélande.

Cette perspective séduit Charrière qui y voit un débouché assuré pour ses concessionnaires en nombre croissant. Ce projet, toutefois, se heurte au scepticisme de Guillain qui, malgré l'insistance du colonel, repousse jusqu'à son départ la ratification du contrat. Ses réticences viendraient, dit-on, des doutes que lui inspiraient les capacités de gestion du directeur de l'Administration pénitentiaire. L'affaire traîne plusieurs années. L'accord est finalement conclu le 13 mars 1870.

Aux termes du contrat le banquier doit construire, à Bacouya, aux portes de Bourail, une usine capable de produire entre 1.000 et 1.500 tonnes de sucre par campagne, qui doit commencer à fonctionner en janvier 1872. Deux ans plus tard, elle devrait atteindre un régime de croisière de 1.500 tonnes de production (Bernard, 1895).

Pour sa part, l'Administration pénitentiaire s'engage à faire cultiver la canne par ses concessionnaires de façon à avoir, en juin 1872, une centaine d'hectares défrichés, pour moitié plantés en cannes prêtes à couper. À partir de 1874, elle devra assurer la totalité des besoins de l'usine. Pour des raisons obscures (peut-être liées à ses doutes sur la capacité du bagne à tenir ses engagements), Cruickshand se dessaisit bientôt de l'affaire qui est alors reprise par Higginson associé à un commerçant d'Adélaide, W. Morgan.

Avec un peu de retard l'usine est finalement montée et peut commençer à fonctionner. La première récolte intervient à la fin de la campagne 1873-1874. L'usine produit 157 tonnes de sucre avec les cannes fournies par la ferme pénitentiaire menée en régie et par les premières plantations des concessionnaires. Car pour tenir ses obligations, en décembre 1870, Charrière a imposé à ses colons de cultiver chacun un hectare de cannes. Cela ne suffisant pas, cette superficie sera doublée ${ }^{1}$. Les concessions pénales couvrant en moyenne 4 hectares, c'est donc le quart, puis la moitié de la concession qu'on doit tenir en canne à sucre. Cette dernière devient ainsi une « culture forcée » du système pénal.

Malgré ces contraintes, la production s'avère incapable de répondre aux espérances de Charrière qui, dit-on, en pleure de rage. Mal conseillés par des agents incompétents, les condamnés n'ont, selon Doucin (1875), «ni planté, ni cultivé la canne à sucre ; leurs récoltes ne leur ont rien rapporté et l'industriel a fait de grandes pertes ». De 1874 à 1877, la récolte ne

1. En 1877 , on ramènera cette obligation à un hectare et demi et, vers 1880 , la culture de la canne deviendra facultative sur les concessions. 
cesse de décliner comme le montrent les résutats publiés dans les notices annuelles de la Transportation $^{2}$ :

\begin{tabular}{|l|c|c|}
\hline $\begin{array}{c}\text { Campagne } \\
\text { sucrière }\end{array}$ & $\begin{array}{c}\text { Sucre } \\
\text { (tonnes) }\end{array}$ & $\begin{array}{l}\text { «Tafia » (rhum) } \\
\text { (hectolitres) }\end{array}$ \\
\hline $1873-1874$ & 157 & 316 \\
\hline $1874-1875$ & 52 & 95 \\
\hline $1875-1876$ & 48 & 157 \\
\hline $1876-1877$ & 25 & $?$ \\
\hline
\end{tabular}

À la fin de 1876, on dénombre seulement 320 hectares de cannes à Bourail où la récolte est de surcroît dévorée par les sauterelles. À partir de là, le déclin s'accuse. Fin 1877, on ne compte que 228 hectares. Entre temps, une partie des concessionnaires se sont détournés vers le café qui leur semble moins aléatoire.

On peut s'interroger sur les raisons de ce précoce déclin. On incrimina les sauterelles dont les invasions étaient devenues périodiques depuis 1867, voire les inondations. L'incompétence des agents de culture de la Pénitentiaire en matière de plantations sucrières, dans la conduite des travaux comme dans la médiocrité des résultats, porte une part de responsabilité. Mais pouvaient-ils réussir là où des spécialistes bourbonnais avaient dû renoncer?

Quoi qu'il en soit, au lieu de décoller, la production s'effondre. En totalisant le poids du sucre et du rhum, parti du niveau 189 tonnes produites en 1874, on tombe au niveau 60 tonnes pour les deux campagnes suivantes.

Devant l'incapacité manifeste de l'Administration pénale à tenir ses engagements, Higginson fait nommer une commission d'enquête qui met en cause les insuffisances et les erreurs commises par l'encadrement pénitentiaire. Ces défaillances induisent un gros déficit pour les industriels qui s'en prévalent pour demander des dommages et intérêts. Sans doute n'étaient-ils pas mécontents d'une issue leur permettant de retirer leur mise de ce guêpier, pour pouvoir la réinvestir dans un secteur minier en plein essor et autrement porteur d'espérances.

Il faut donc évaluer le préjudice subi. Devant l'énormité de la somme, force est de transiger. Faute d'argent, Charrière offre de payer en nature. Accord conclu. En 1877, l'Administra- tion pénitentiaire rachète l'usine de Bacouya en cèdant à Higginson, pour 20 ans, 300 forçats destinés à travailler sur ses mines de cuivre de La Balade dans l'extrême-nord de la Grande Terre, près de Ouégoa. Moyennant quoi, l'industriel renonce à toute réclamation financière.

Cette transaction est à l'origine de ces scandaleux contrats, dits " de chair humaine» que la Pénitentiaire va multiplier. Étrange solution qui « au lieu de cannes à sucre à fournir à l'entrepreneur de Bourail », consiste à livrer « 600 bras au propriétaire de La Balade» (Lemire, 1884). C'est ainsi qu'en 1877, l'Administration pénitentiaire récupère l'usine de Bacouya avec charge de la faire fonctionner. Il ne pouvait plus être question de l'arrêter car, « après avoir encouragé les concessionnaires à planter la canne, parce qu'on avait acquis une usine, il fallait bien garder l'usine pour que les concessionnaires puissent écouler leurs cannes » (Mimande, 1897).

C'est sans illusion que l'Administration pénitentiaire reçoit l'encombrant héritage de cette usine vacillante. La notice de la Transportation pour 1877 considère comme «aujourd'hui douteux que l'industrie sucrière puisse s'acclimater en Nouvelle-Calédonie ». Et Charrière d'annoncer au même moment qu'on allait réduire l'obligation de planter des cannes, de 2 à 1,5 hectares. Peu après, cette contrainte sera même supprimée. L'année précédente, déjà, la Pénitentiaire, déçue par les premiers résultats de sa chimère sucrière, avait commencé à regarder vers le café, pensant qu'il deviendrait la culture dominante à Bourail. Elle avait même fait préparer, en face de Bacouya, de vastes pépinières d'arabica. Paradoxalement, c'est alors qu'il commence à douter du sucre que le bagne hérite de la sucrerie.

Dans ce contexte, les campagnes suivantes ne sont guère enthousiasmantes. On remonte au niveau d'une centaine de tonnes (sucre et tafia) en 1878. Mais, avec l'insurrection, on replonge l'année suivante. En 1880 on est à 16 tonnes. C'est la chute verticale jusqu'en 1881 où, avec 3,5 tonnes de sucre, épargnées par les criquets et les inondations, on touche le fond. $\mathrm{Ce}$ piètre résultat représente cependant l'effort de 300 condamnés employés aux cultures et d'une centaine d'autres travaillant à l'usine (Godey, 1886).

2. La confusion entre des résultats donnés par campagne sucrière, ou par année civile sans préciser la période, conduit à d'inextricables contradictions selon les auteurs. Ainsi, d'après Godey (1886), la production de sucre aurait été, en 1874, de 16 tonnes. Selon les sources, des divergences parfois importantes apparaissent pour une même période. À propos de la campagne sucrière 1883-1884, Legrand (1893) indique 109 tonnes de sucre et 803 hectolitres de "tafia », tandis que la Notice de la Transportation avoue 65 tonnes et 1.292 hectolitres de rhum. 
Productions annuelles de Bacouya de 1878 à 1882 (Alberti, 1909).

\begin{tabular}{|l|c|c|}
\hline Année & $\begin{array}{c}\text { Cannes manipulées } \\
\text { (tonnes) }\end{array}$ & $\begin{array}{c}\text { Sucre + rhum } \\
\text { (tonnes) }\end{array}$ \\
\hline 1878 & 2.686 & 97,5 \\
\hline 1879 & 3.386 & 46 \\
\hline 1880 & 1.863 & 37,7 \\
\hline 1881 & $?$ & $(3,5$ t de sucre) \\
\hline 1882 & 3.012 & 16,9 \\
\hline 1883 & 2.899 & 196 \\
\hline
\end{tabular}

Simultanément, la surface plantée en cannes régresse. Elle couvrait à Bourail 228 hectares en 1877. En 1880-1881 elle est d'une cinquantaine d'hectares.

La mauvaise qualité du sucre produit, moqué sous le vocable de "colle de Bourail» (Bernier, 28/1/1885), la baisse des cours du sucre à partir de 1883 , les mécomptes économiques et la priorité désormais accordée aux travaux de routes dans l'affectation de la main-d'œuvre pénale, semblent sonner le glas de la culture sucrière. D'autant que, de tous côtés, on dénonce le coût élevé des pénitenciers agricoles.

L'heure est au désenchantement. En 1882, avec l'approbation du ministère (Dépêche du 20/2/1883), l'Administration pénitentiaire, pourtant à l'apogée de sa puissance, prend plusieurs mesures pour restreindre la culture de la canne à Bourail. La plus significative est le renoncement à la gestion directe de l'usine.

Dans l'espoir d'améliorer sa rentabilité, Bacouya est alors confiée à un homme d'expérience qu'on promeut «directeur spécial». Il s'agit du sucrier bourbonnais Saturnin Maillot, un collaborateur d'Evenor de Greslan, en charge auparavant de la sucrerie de Koé à la Dumbéa, (qui vient de cesser son activité à la suite des ravages des sauterelles).

Ce changement à la tête de l'usine s'imposait. Dans un rapport ultérieur, l'inspecteur des colonies Leclos (1884) dira la nécessité « que l'usinier fut administrateur et qu'il réglât seul la conduite de l'établissement ». Et de fait un souffle de renouveau anime alors la vieille institution.

\section{La gestion indirecte de Bacouya et l'éphémère renouveau (1882- 1885)}

Le retrait de l'Administration pénitentiaire, la compétence du nouveau gérant, le sentiment que les sauterelles ont disparu, créent un climat de confiance que traduit une relance éphémère de la production. Ragaillardie, l'Administration pénitentiaire incite à nouveau ses colons à planter des cannes. La superficie couverte par ces plantations double, retrouvant la centaine d'hectares. La productivité des plantations augmente aussi. Entre 1879 et 1881, la quantité de sucre produit à l'hectare était de l'ordre d'une tonne. En 1883, elle quintuple, s'élèvant à 5,4 tonnes (Savoie, 1922). Les années suivantes, on tire encore entre 4 et 6 tonnes de sucre à l'hectare. Dans ce contexte, la production de sucre grimpe à 109 tonnes en 1883 et l'on attend son doublement pour la récolte suivante (Notice de l'Exposition d'Anvers, 1885). On produit aussi à Bacouya 300 hectolitres d'un rhum d'excellente qualité (O'Reilly, 1980).

Cette embellie est largement imputable à ce que l'on pourrait appeler « l'effet Maillot». Ce dernier a pris les choses en main, lutte contre les vols et les détournements, améliore le matériel vétuste de l'usine, dénonce l'inefficacité de la main-d'œuvre pénale qu'il tente de remplacer par des Indochinois (O'Reilly, 1980). Mais ce regain d'intérêt coïncide aussi avec l'atténuation des grandes calamités, notamment la disparition des vols de sauterelles, avec le retour d'un cycle plus humide.

Bourail connaît alors un souffle d'optimisme dont témoigne un rapport anonyme (rédigé vers 1885) : «L'opinion générale est que l'industrie sucrière n'a pas dit son dernier mot en NouvelleCalédonie. Les vallées se prêtent à la culture de la canne; les sauterelles ont disparu grâce aux mesures énergiques et aux primes ; les sècheresses peuvent être combattues par l'irrigation; la mécanique industrielle peut supplanter le travail manuel hors de prix » (Archives FOM. N-C Cart. 151) ${ }^{3}$.

Le sentiment prévaut alors que l'industrie sucrière « arrêtée dans son développement par l'insurrection canaque et les sauterelles, semble vouloir prendre aujourd'hui un nouvel essor $»$. C'est le ministre Félix Faure qui parle ainsi (Dépêche du 17 novembre 1884), poursuivant:

3. Raoul (1889) confirme cette euphorie : « Longtemps arrêtée dans son essor et pour ainsi dire anéantie par l'invasion des sauterelles, puis par la baisse des cours sur le sucre survenue en 1883, l'exploitation de la canne à sucre tend à reprendre en Nouvelle-Calédonie. Il serait même possible qu'en transformant l'outillage actuel, la fabrication du sucre devint une industrie d'un grand profit [...]. Quoi qu'il en soit, dans les très bonnes terres calédoniennes on peut récolter jusqu'à 135 tonnes de cannes à l'hectare. Les sirops peuvent donner 1.550 litres de tafia dont le prix dans la colonie n'est pas inférieur à 0,50 franc. Quant au sucre, le prix des grosses adjudications se rapproche en général de 450 francs la tonne ». 
« Il importe que les usines de Bourail et de Koé soient outillées de façon à faire face à tous leurs besoins [...] Mes dépêches du 20 décembre 1883 et du 30 avril 1884 ont prescrit de donner à ces établissements tout le personnel et le matériel nécessaire pour assurer la manipulation de la canne en $1884 »$.

En 1884, on se propose de remplacer tout le matériel et les appareils de Bacouya «par ceux, perfectionnés, en usage à la Réunion et à la Martinique ». Mieux, le ministre en est à envisager la création de nouvelles sucreries. Il évoque «la possibilité d'installer une nouvelle usine à sucre sur le centre de Boghen » et des industriels entrent en pourparlers avec l'Administration pénitentiaire, en vue d'implanter deux sucreries, l'une à Moindou, l'autre à La Foa (Gallet, 1884). Aucun de ces desseins n'aboutira.

Le ministre reviendra, plus tard, sur la rénovation souhaitable de Bacouya. Le 9 juillet 1886, il écrira au gouverneur Nouet: "J'ai lieu de croire que vous vous préoccuperez de développer la canne à sucre à Bourail et de mettre l'usine de Bacouya en état de manipuler chaque année toutes les récoltes qui pourraient être livrées par les concessionnaires [...]. Je n'ignore pas que l'outillage de l'usine de Bacouya est actuellement assez défectueux, mais dès que la situation du 'Budget sur ressources spéciales' le permettra, j'ai l'intention de faire acheter un matériel complet et perfectionné de façon à assurer une exploitation sérieuse, régulière et étendue » (Arch. FOM N-C Cart. 25).

En ces temps d'euphorie, renaissent les grands projets d'équipement. Outre la remise à neuf du moulin de Bourail décrit comme « fort coûteux et absolument arriéré » (Quinzaine coloniale, $25 / 3 / 1898$ ), on envisage de nouveaux défrichements pour augmenter l'approvisionnement de cette usine. C'est ainsi qu'on défriche et draine le «marais Péré ». Une plantation nouvelle de 13 hectares de cannes et de maïs y est établie, portant à 70 hectares la superficie des terrains de l'Administration pénitentiaire plantés en cannes dans ce secteur (Notice de la Transportation, 1885). En outre, comme l'on imputait une part de l'échec antérieur au manque de routes qui rendait les transports difficiles et onéreux (Gallet, 1884), on étudie, en 1884, un projet de chemin de fer Decauville pour relier l'usine aux concessions éloignées et réduire le temps de transport des récoltes.
Au diapason de ces projets, en 1885, les agents de culture du bagne élaborent un programme de production sur six ans, prévoyant la manipulation de 2.000 à 3.000 tonnes de cannes, à partir des seules plantations administratives ${ }^{4}$.

La production de cannes était, en effet, assurée conjointement par l'Administration, sur ses fermes pénitentiaires, et par les colons pénaux installés sur les concessions. Mais la part directement cultivée par l'Administration ne cesse d'augmenter, surtout à partir du moment où la culture forcée cesse d'être imposée aux concessionnaires. En 1884-1885, avec 1.088 tonnes sur une récolte de 1.306 tonnes, cette part de l'Administration représente $83 \%$ de la production cannière à Bourail (Notice de laTransportation, 1885). Autant dire que c'est l'Administration qui fait tourner l'usine.

Par cette activité, l'Administration pénale entend démontrer l'efficacité de son rôle comme moteur de développement. C'est, pour elle, une façon de s'affirmer indispensable et de justifier l'énorme dotation foncière dont elle vient de bénéficier avec le décret du 16 août 1884 lui attribuant un domaine de 110.000 hectares à travers l'île.

Elle espère toujours fonder la prospérité agricole sur l'exportation. Souci qui s'exprime dans la notice qu'envoie le Gouverneur le 26 novembre 1884, à l'occasion de l'exposition universelle d'Anvers : "La culture de la canne à sucre ", écrit-il, « doit être poursuivie avec persévérance en vue de doter la colonie d'un produit d'exportation [...]. La Transportation, afin de venir en aide, aussi bien à ses concessionnaires qu'à la colonisation libre, s'est placée à la tête du mouvement qui se produit en faveur du relèvement de l'industrie sucrière et, usant des moyens dont elle dispose, assure actuellement le fonctionnement des deux seules usines qui existent dans la colonie, Bourail et Koé. Le jour approche, il faut l'espérer, où la culture de la canne sera définitivement implantée dans le pays ; la Transportation aura rendu un nouveau service à la Nouvelle-Calédonie ».

Mais tout cela n'est que rêve. Les mécomptes ne vont pas tarder à doucher les enthousiasmes. Malgré le savoir-faire de Maillot, lentement mais inexorablement, la lourde machinerie s'enlise.

4. Ces prévisions se présentaient ainsi (Notice de la Transportation, 1885) :

\begin{tabular}{|l|c|c|}
\hline Années & Superficie plantée en cannes (ha) & Production en cannes (tonnes) \\
\hline 1886,1888 et 1890 & 46 ha & $3.220 \mathrm{t}$. \\
\hline 1887,1889 et 1891 & 31 ha & $2.170 \mathrm{t}$. \\
\hline
\end{tabular}




\section{Le déclin de Bacouya (1886-1900)}

L'engouement pour la canne du milieu des années 1880 est un feu de paille.

Parlant de Bacouya, un rapport (Anonyme, 1885) montre les limites de la rémission apparue après 1882 : «Cet établissement n'a jamais cessé de fonctionner dans des conditions défectueuses provenant surtout de l'insuffisance et du mauvais état du matériel [...]. La campagne de 1880 a donné 3 tonnes environ de sucre et, depuis cette époque, le rendement, quoique meilleur, est loin de compenser les frais d'exploitation » (Arch. FOM. N-C Cart. 151).

La baisse des cours du sucre n'est pas un phénomène conjoncturel. Elle s'inscrit dans la durée. Elle rend compte d'une évolution des structures du secteur sucrier. Avec la révolution industrielle en Europe, l'essor de la culture betteravière transforme la production de sucre en production de masse. L'heure est à la concentration et partout au remplacement des anciens moulins par de puissantes usines centrales. Les « petites usines à vieux matériel », isolées comme celles de Calédonie, deviennent obsolètes. À tel point qu'à Bourail comme à Koé, on se détourne peu à peu du sucre pour s'orienter vers la distillation et la production de rhum que l'on croit plus facile à rentabiliser (Notice de l'Exposition, 1900). Bacouya produit ainsi, en 1888, 200 tonnes de sucre et 3.000 hectolitres de "tafia". Usées, démodées, les usines pénitentiaires coûtent cher. Le rapporteur du budget des Colonies pour 1884 réclame leur suppression, tant leur production, intermittente, reste dérisoire. Parlant de Bacouya, E. Davillé (1901) note qu' « elle n'est guère utilisée que par les concessionnaires en cours de peine ou libérés, et fournit à peu près ce qu'il faut comme cassonade et comme tafia pour la consommation des rationnaires ». Et encore pas toujours. En 1885, elle n'a pu livrer à l'Administration pénitentiaire tout le tafia dont celle-ci avait besoin. On dut en acheter dans le commerce (Arch. FOM. N-C Cart. 25). Plus tard, en pleine période Feilletiste où l'heure est à la dénonciation du bagne, la notice pour l'exposition de 1900 ne se privera pas de persifler une entreprise qui « occupe les condamnés mais ne produit que peu de choses $»$.

Le 31 juillet 1890, Saturnin Maillot s'étant retiré, l'Administration pénitentiaire met Bacouya en adjudication. L'usine échoit à un colon d'origine pénale qui fait faillite. Elle retombe donc entre les mains de la Pénitentiaire, encombrée de ce fardeau, alors que l'on s'apprête à lui supprimer le budget sur ressources spéciales. À partir de là, la canne cesse de figurer dans la liste des cultures pénitentiaires pratiquées à Bourail où désormais maïs et haricots dominent à côté d'un peu de café, de chanvre, de lin, de choux et surtout de tabac.

Quatre ans plus tard, la Pénitentiaire cèdera l'usine à un particulier «beaucoup plus sérieux ». Ce dernier fera, dit-on, "de bonnes affaires » et son tafia "connu sous le nom de 'rhum de Bacouya', jouira d'une juste réputation dans le pays » (Notice de l'Exposition, 1900).

Ce n'est pourtant qu'un dernier sursis. En 1902, l'usine de Bacouya ferme définitivement. La Quinzaine coloniale (25/8/1902) mentionne en guise d'épitaphe que « la réouverture de la distillerie de Bacouya n'a pas suscité les espoirs mis en elle, et [qu'] après avoir donné en abondance un rhum d'une excellente qualité, elle vient d'être abandonnée ».

On ne saurait clore le chapitre des avatars sucriers de la Pénitentiaire en NouvelleCalédonie sans évoquer brièvement l'autre usine qu'elle eut à gérer à Koé, à dix-huit kilomètres de Nouméa.

\section{Le moulin de Koé (1879-1890)}

En 1879, l'Administration pénitentiaire qui, depuis deux ans, gérait Bacouya, étend ses activités agricoles à la vallée de la Dumbéa. Elle est alors en phase de montée en puissance après la grande insurrection. Et là, elle retrouve son partenaire, Higginson.

Les anciennes habitations sucrières de KoéNimba appartenant aux Bourbonnais Evenor de Greslan et Numa Joubert ${ }^{5}$ avaient été rachetées par Higginson en 1877 après que celles-ci aient été mises en vente sur saisie mobilière. La culture de la canne avait été abandonnée à Nimba, suite aux ravages des sauterelles.

Malgré l'opposition des colons de la Dumbéa qui pétitionnent (vainement) contre l'installation du bagne, craignant pour leur sécurité et redoutant, plus encore, la concurrence que représentait la venue des forçats, le 18 mars 1879 , l'Administration pénitentiaire loue à Higginson ses propriétés de Koé-Nimba, de la plaine Adam et la station d'élevage de Koutio-Kouéta. Il s'agit d'un contrat de métayage valable pour 10 ou 20 ans permettant ainsi d'établir un pénitentier agricole (Savoie, 1922).

5. La propriété Numa Joubert, à Koé, avait été mise en vente le 25 juillet 1877 après que, le 4 juillet 1877, un inventaire minutieux ait été publié dans le Moniteur. Quant à F. Joubert, il était mort dès 1873 sur sa propriété de Koutio-Koueta, elle aussi rachetée par Higginson (O’Reilly, 1953). 
Le nouvel établissement couvrait 3.358 hectares, dont 993 ha à Koé où se trouvait l'ancienne usine Joubert et où l'Administration établit ses apprentis-concessionnaires sous la direction d'un agent de cultures en vue de les former avant leur mise en concession. Il y avait aussi 132 ha à Nimba, 497 ha à la plaine Adam et 1.736 ha. à Koutio-Koueta, domaine affecté au bétail et à l'élevage des jeunes chevaux (où l'on dénombrera 14 chevaux, 96 bovins et 215 chèvres en 1887) (Turquet, 1888).

Cet ensemble de propriétés comportait environ 1.500 hectares cultivables dont seulement 268 avaient été exploités ( 26 ha en fourrages; 126 ha d'anciennes plantations de cannes; 45 ha de cultures arbustives et de plantes annuelles diverses, et 75 ha d'usages divers). Ce vaste domaine était donc largement sous-exploité.

À Koé, la Pénitentiaire n'envisageait pas, au départ, de rétablir les plantations de cannes qui avaient été abandonnées par suite des dégats des criquets. Il y avait à Koé, près d'un gisement de glaise, une briqueterie et un potager. Dans les premiers temps l'Administration poursuivant sur ces brisées, produisit des briques et créa une exploitation maraîchère. Mais, plusieurs artisans (briquetiers) du Mont d'Or et divers maraîchers nouméens s'estimant illégalement concurrencés par la main-d'œuvre pénale, se plaignirent au Gouverneur. La ferme pénitentiaire de Koé cessa dès lors de produire pour le marché nouméen et revint à la canne à sucre. Les sauterelles n'inquiétaient pas le bagne qui pensait avoir les effectifs adéquats pour les réduire.

En 1880, délaissant l'ancien moulin hydraulique de Joubert à Nimba, l'Administration pénitentiaire entreprend de construire une nouvelle usine à vapeur, près du camp de Koé. L'outillage est transformé et de nouvelles plantations de cannes commencent à couvrir la plaine environnante. Cinq ans plus tard, 46 hectares sont en exploitation et 32 autres plantés pour parvenir à maturité en 1887.

La Dumbéa connaît à son tour un vent d'optimisme. La reprise de Koé par l'Administration pénitentiaire et la construction du nouveau moulin suscitent l'intérêt des colons environnants, dont certains s'inquiétent de savoir si leurs propres cannes pourraient aussi être traitées par l'usine. La sucrerie de Koé connut quelques années fastes, produisant du sucre et un tafia apprécié, connu sous le nom de «Rhum de Koé ». Les résultats restaient cependant modestes eu égard aux possibilités du domaine. La première roulaison, en 1883 , donna 80 tonnes de sucre et 800 litres de tafia (Notice de l'Exposition d'Anvers, 1884). On espérait arriver à produire
400 tonnes de sucre et 400 hectolitres de rhum les années suivantes. Mais ce niveau ne fut jamais atteint.

Au contraire, on dut bientôt abandonner la fabrication du sucre jugée non rentable. Par contre, celle de rhum fut développée, soutenue par la réputation du produit reconnu supérieur au tafia de Bourail. Elle devint la spécialité de Koé. Pourtant, bien que prisée, cette production resta modeste et d'une rentabilité incertaine.

À partir de sources disparates, nous avons pu retrouver quelques indications sur la production annuelle de l'usine de Koé :

\begin{tabular}{|l|c|c|l|}
\hline Année & $\begin{array}{c}\text { Tonnes } \\
\text { de sucre }\end{array}$ & $\begin{array}{c}\text { Hectolitres } \\
\text { de rhum }\end{array}$ & \multicolumn{1}{|c|}{ Sources } \\
\hline 1883 & 80 & 8 & Notice Exp. Anvers \\
\hline 1884 & 20 & 62 & Not. Transp. \\
\hline 1885 & 8 & 116 & Not. Transp. \\
\hline 1887 & 105 & 1.000 & Legrand 1890 \\
\hline
\end{tabular}

Non contente d'être faible ou irrégulière, cette production revenait cher. En 1888, le prix du tafia de Bourail et de Koé était tellement supérieur à celui du commerce local que l'armée préféra se fournir chez les commerçants de la ville. Plus grave, malgré ce prix élevé, les établissements pénitentiaires de la Dumbéa furent constamment lourdement déficitaires. Entre 1879 et 1885 , les recettes ne s'élevaient qu'à 200000 francs quand les dépenses atteignaient 370000 francs (Instructions à Nouet, 9/7/1886). $\mathrm{Au}$ total, le déficit conjugué des deux usines de Koé et de Bacouya devait coûter près de 5 millions à l'Administration pénitentiaire.

Devant ce coût et l'insignifiance des résultats, le gouvernement local et l'Administration pénitentiaire se rendent à l'évidence, les usines ne seront jamais rentables. On a cessé, jusqu'en haut lieu, de croire à la canne dont chacun, à présent, se détourne. Le 26 août 1889, le ministère enjoint de renoncer aux usines et de résilier le bail de Koé. Le 31 juillet 1890, l'Administration pénitentiaire rompt le contrat. Mais contrairement à Bacouya jadis, les domaines de la Dumbéa, usine en prime, reviennent à leur propriétaire, Higginson. Quatre ans avant Bourail, le désengagement sucrier du bagne est, ici, total.

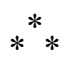

En 1894, la Pénitentiaire a cessé de croire au sucre et la canne s'efface de la nomenclature des cultures pénales. La survie de Bacouya, une décennie encore, n'est qu'une lente agonie et, son 
ultime sursis après 1894, une affaire strictement privée. La chimère d'une Calédonie sucrière a définitivement vécu.

Désormais, les concessionnaires pénaux ont leur destin tout tracé : de La Foa à Bourail et à Pouembout, pour un demi-siècle encore, ils reviendront au maïs et aux haricots, destinés aux gamelles des rationnaires ou au marché local, dont la culture n'avait jamais cessé entre les champs de cannes. Au fil des ans, ils y adjoindront des légumes, du tabac, du coton, enfin, du café.

Mais, en ce $\mathrm{XIX}^{\mathrm{e}}$ siècle finissant, au terme des années de plomb de l'hégémonie pénitentiaire, le café porte surtout la nouvelle chimère, l'avènement de la petite colonisation libre attendu en vain depuis cinquante ans. Succèdant à la canne et au sucre des riches créoles bourbonnais puis des tacherons besogneux de la Pénitentiaire (nonobstant un bref engouement cotonnier entre les deux guerres mondiales), le café marquera jusqu'au déclin du $\mathrm{xx}^{\mathrm{e}}$ siècle le dernier grand cycle agricole de la Calédonie coloniale et le premier chemin des Kanaks vers l'intégration monétaire.

\section{BIBLIOGRAPHIE}

Anonyme, I 885. Compte rendu des délibérations de la chambre d'agriculture (juin-juillet 1885), Arch. Nat. SOM Carton 151.

BERNARD, 1895. L'archipel de la Nouvelle-Calédonie, Hachette, Paris, 459 p.

Bernier J., 1885. Journal Le Néo-Calédonien, Nouméa. 28 janv. 1885.

DAVILlÉ E., 1901. Guide pratique du colon en NouvelleCalédonie, J. André, Paris, 215 p.

Doucin E.,1875. « Des essais de colonisation pénitentiaire en Nouvelle-Calédonie ». Communication au Congrès de L'Association française pour l'avancement des sciences. Séance du 25 août 1875 . Compte rendu. Paris, pp. 1307-1315.

GaLLET G., 1884. " Notice sur la NouvelleCalédonie », Imprimerie du Gouvernement. Nouméa, $59 \mathrm{p}$.
GoDEY Ch., 1886. Tablettes d'un ancien fonctionnaire de la Nouvelle Calédonie (2 vol). Challamel. Paris, tome $1341 \mathrm{p}$. ; tome 2, $361 \mathrm{p}$.

LECLOS (Inspecteur), 1884. « Rapport d'inspection au Ministre ». Législation de la Nouvelle-Calédonie, 1904. Tome IV, 258 p.

Legrand M.A., 1893. Au pays des Canaques. La Nouvelle Calédonie et ses habitants en 1890, L. Baudoin, Paris, 212 p.

Lemire C, 1884. Voyage à pied en Nouvelle-Calédonie et description des Nouvelles-Hébrides, Challamel, Paris, 298 p.

Mimande P., 1897. Criminopolis, Calmann-Levy, Paris, 319 p.

Ministère de LA MARINE ET DES COLONIES, 1885. Notices coloniales publiées à l'occasion de l'exposition universelle, en 1885. Tome deuxième: NouvelleCalédonie, Imprimerie nationale, Paris, pp. 117226.

_, 1871-1901. «Notices de la Transportation à la Guyane française et à la Nouvelle Calédonie », Imprimerie nationale. Paris.

O’Reilly P., 1980 ( $2^{\mathrm{e}}$ ed). Calédoniens, Société des Océanistes, Paris, 418 p.

O’Reilly P, 1953. Calédoniens, Société des Océanistes, Paris, 305 p.

Raoul E., 1889. "La Nouvelle Calédonie », Exposition coloniale de 1889, Les colonies françaises, tome 4 : «Colonies et Protectorats de l'Océan Pacifique », Maison Quantin, Paris, 124 p.

Saussol A., 1985. «Colonisation rurale et problème foncier en Nouvelle-Calédonie », tome 2 : « Les systèmes de colonisation ", Thèse d'État, Bordeaux, multigr., pp. 262493.

Savoie C, 1922. «Histoire de la Nouvelle-Calédonie et de ses dépendances, sous les gouverneurs militaires (1853-1884) », Nouméa, Imprimerie nationale, 247 p.

Turquet E., 1888. Nouvelle Calédonie, Revue Pénitentiaire, Paris, pp. 442-478 et pp. 889-996.

UNION AGRICOLE CALÉDONIENNE, 1900. « Notice sur la Nouvelle-Calédonie, ses richesses, son avenir, rédigée pour l'Exposition universelle de 1900 », Société d'éditions littéraires et artistiques, Paris, $210 \mathrm{p}$. 